\title{
Registres du Conseil de Genève à l'époque de Calvin (tome II: 1537), texte établi par Paule Hochuli Dubuis et Sandra Coram-Mekkey
}

Michele Mastroianni

\section{(2) OpenEdition Journals \\ Edizione digitale \\ URL: https://journals.openedition.org/studifrancesi/37387 \\ DOI: 10.4000/studifrancesi.37387 \\ ISSN: 2421-5856 \\ Editore \\ Rosenberg \& Sellier}

\section{Edizione cartacea}

Data di pubblicazione: 15 décembre 2004

Paginazione: 590

ISSN: 0039-2944

\section{Notizia bibliografica digitale}

Michele Mastroianni, «Registres du Conseil de Genève à l'époque de Calvin (tome II: 1537), texte établi par Paule Hochuli Dubuis et Sandra Coram-Mekkey», Studi Francesi [Online], 144 (XLVIII | III) | 2004, online dal 30 novembre 2015, consultato il 08 mai 2021. URL: http://journals.openedition.org/studifrancesi/ 37387 ; DOI: https://doi.org/10.4000/studifrancesi.37387

Questo documento è stato generato automaticamente il 8 mai 2021.

\section{cc) (†)}

Studi Francesi è distribuita con Licenza Creative Commons Attribuzione - Non commerciale - Non opere derivate 4.0 Internazionale. 


\title{
Registres du Conseil de Genève à l'époque de Calvin (tome II: 1537), texte établi par Paule Hochuli Dubuis et Sandra Coram-Mekkey
}

\author{
Michele Mastroianni
}

\section{NOTIZIA}

Registres du Conseil de Genève à l'époque de Calvin (tome II: 1537), texte établi par PAULE HOCHULI DUBUIS et SANDRA CORAM-MEKKEY, Genève, Droz («Travaux d'Humanisme et Renaissance», $n^{\circ}$ CCCLXXXVI), 2004, pp. 761, in 2 voll.

Continua l'impresa (cfr. questi «Studi», 140, 2003, p. 430) della pubblicazione dei registri dei rendiconti delle sedute del Petit Conseil della città di Ginevra all'epoca di Calvino. Il secondo tomo offre il materiale dell'anno 1537, che occupa due registri costituiti da una serie di quaderni che sono stati assemblati e foliotati nell'Ottocento. Sono quasi sempre della mano del segretario Claude Roset. Oltre al valore storico, che ho già indicato nella precedente segnalazione, mi pare opportuno sottolineare, data la destinazione dei nostri «Studi», l'interesse di documento linguistico di questi rendiconti. Infatti, benché dalla fine dell'anno 1536 essi siano redatti essenzialmente in francese - e solo nel gennaio e febbraio 1537 compaiano ancora numerosi passi in latino -, a partire dal marzo 1537 è il francese che si impone, anche in seguito alle disposizioni del Petit Conseil del 1536 di non redigere in latino: tuttavia il volgare è mal padroneggiato (addirittura i prosegretari che rimpiazzano talvolta Claude Roset lo scrivono in maniera fonetica) e lo storico della lingua ha una testimonianza di primo piano sull'apprendimento e sulla lenta affermazione del volgare in documenti ufficiali cinquecenteschi, in un'area marginale rispetto a quella della francofonia. Come nel 
primo tomo, il ricchissimo indice dei nomi offre uno strumento utilissimo di lavoro allo storico (anche allo storico della letteratura). 